show their unambiguous support for nuclear disarmament. Confessing "the part played by science in the development of weapons of mass destruction and the failure of the churches to oppose it", the delegates were unanimous in their endorsement of a resolution (drafted by a committee chaired by Dr J Habgood, Bishop of Durham) that called for full implementation of SALT II, advocated SALT III, supported UN initiatives on disarmament and opposed the development of new nuclear weapons. However, one proposal for unilateral disarmament was overwhelmingly defeated.

The other aspect of the nuclear problem, the 'peaceful' uses of atomic energy, also led to lively controversy. Professor David Rose, of MIT, argued for the continued use of nuclear energy at least until solar energy is developed, which means in practice, for several decades. But Professor J Rossel, a Swiss physicist, argued equally strongly against its use. Not surprisingly the section report concerned with this issue was divided and at the plenary session a keen debate resulted in the passing of a resolution, by a $129-45$ vote, that called for a 5-year moratorium on the construction of nuclear power plants. My impression was that this majority included a large number of votes from among the 100 student representatives who, although neither strictly delegates of their churches, nor appointed as experts, had full voting rights.

The students, from 55 nations, had met before the conference at Wellesley College, Boston, to discuss the key issues. They asserted inter alia that science education is not tying social values to the teaching of technology and this theme was also heard when they reported their views to the main meeting. They were again especially critical of science education which they saw as an elitist weapon used to preserve power and institutionalised values.

This raises the wider question of how representative the conference was. But, representative of whom? Certainly it voiced the profound concerns about science and technology of many active members of the Christian churches across the world, which, it must be stressed, are increasing rapidly in the Third World. It is difficult for such a conference to claim to be 'representative', but it might nevertheless aspire to leadership of opinion resulting in action. If it does, the hopes over many years of the devoted staff of the WCC (and one thinks particularly of Dr P Abrecht, the director of the Church and Society unit that was responsible) will have been justified. And, in the end, the most remarkable thing about this unique conference is not so much its plethora of resolutions and its section reports (yet to be published) but the fact that it was held at all - and in MIT. The relation of the Christian churches to modern science and technology can never be quite the same again.

\section{Can biogas provide energy for India's rural poor -}

or will it benefit only richest $10-12 \%$ of rural families? Anil Agarwal reports on the Janata government's plans to promote the use of biogas plants

INDIA has the world's second largest biogas programme, surpassed only by China, and its interest in bio-gas has probably the longest history. Although the first bio-gas plants were designed in 1939, the Khadi and Village Industries Commission was able to establish only 6,000 plants by 1974 . The energy crisis of that year, which sent the price of kerosene soaring above the purchasing power of rural Indians and pushed them further into the environmentally disastrous use of firewood, persuaded the government of India to promote bio-gas plants more seriously.

In the last five years, over 75,000 bio-gas plants have been set up, and during the sixth five year plan (1978-83), the government hopes to establish 500,000 plants at a total cost of Rs 2175 million $(\operatorname{Rs} 17.7=£ 1)$. About a third of this sum will be provided by the KVIC and the Ministry of Agriculture as grants, the rest being raised through loans from banks. These plants will create an annual production capacity equivalent to 750 million litres of kerosene. In addition, they will generate about 12 million tonnes of organic manure, which otherwise would have been burnt as cowdung cakes for fuel.

The programme should provide jobs for over 2,000 educated unemployed people and some 40,000 skilled and semi-skilled workers.

But compared to the total bio-gas potential within the country, the current rate of utilisation is extremely slow, much slower than China, which is reported to have set up over seven million bio-gas plants in a few years. Mr T.L. Sankar, secretary of Planning Commission's working group on energy policy, estimates that India has a potential of at least $18,750,000$ family size bio-gas plants and 560,000 community size plants (with daily capacities of 1.7 and 142 cubic metres of gas respectively). While the family size plants could be used by richer rural households (with 4-5 head of cattle), the community size plant could supply energy to poorer households.

If this potential were realised by 1990 , bio-gas could supply India with an energy equivalent to nearly $44 \%$ of its projected electricity consumption, and reduce its

\section{Sorry, for copyright \\ reasons some images on this page may not be available online}

Mound of cowdung cakes: a traditional source of fuel

projected consumption of coal by $15 \%$ and firewood by $79 \%$. The use of firewood would be reduced to an environmentally safe level, saving forestry expenditure, and the organic manure by-product would also reduce expenditure on chemical fertilisers. Although the investment required to adopt this option would be very high, about Rs 66,000 million. Mr Sankar believes that an energy policy that places high emphasis on bio-gas plants would have the "highest cost-benefit ratio".

To promote the use of bio-gas plants, the KVIC has started a self-employment scheme under which educated unemployed persons are being given training in installation and commissioning. They are paid Rs 180 for supervising the installation of each gas plant. The KVIC takes a deposit of Rs50 as security before they begin work and retains $25 \%$ of their supervision charges until the total security reaches Rs500. These 'motivators' are expected to rectify all defects in the plants they have supervised, within the first three months of commissioning, at their own cost. Through this scheme, the KVIC hopes that greater care will be taken at the time of construction and thus maintenance and breakdown problems should be reduced; it claims that this scheme has given "very good results". Over 1500 motivators have already been trained.

\section{Problems of managing community plants}

But achieving Mr Sankar's target could be very difficult. There appear to be serious socio-economic obstacles to the widespread use of bio-gas plants. Past experience has shown that small family-size plants can be used only by the richest $10-12 \%$ of rural families. The large-scale use of bio-gas plants could drive poorer families to a greater reliance on the dwindling 
supplies of firewood, as their present cowdung fuel becomes unobtainable.

Ironically, while the Chinese have unhesitatingly promoted the use of small plants, appropriate technologists in India have argued that only large community plants can benefit the Indian rural poor. But such plants require great managerial talents for their maintenance and operation, for the organisation of the collection of cowdung, valuation of the dung which would have to be purchased, and sale of the gas and manure generated. Furthermore, sociologists still have to explain what motivated those farmers who have bought bio-gas plants. While some reports say that the initiative comes largely from women, who like bio-gas as a clean fuel, other reports claim that farmers buy bio-gas plants because it provides them with organic manure for their fields, and regard the gas only as a by-product.

With financial assistance from UNICEF, two large prototype plants $\left(30 \mathrm{~m}^{3}\right.$ and $45 \mathrm{~m}^{3}$ respectively) have been built in the village of Fatehsingh ka Purwa in Etawah district. Bio-gas from these plants will provide cooking energy for the 200 inhabitants of the village as well as energy for running threshers, chaff cutters, mini-four mills, and for pumping water and generating electricity for street and home lighting. Fatehsingh ka Purwa is mainly a village of cowherds and the ratio of cattle to man is relatively high, which makes it possible for bio-gas alone to supply energy for so many activities. The total cost of the project is Rs 158,000. Each family will receive slurry from the bio-gas plants in proportion to the cowdung it supplies. Bio-gas will be supplied free for two years and thereafter the villagers are expected to contribute. Few villagers at the moment appear to be prepared to pay anything for their energy, the concept of paying for fuel being traditionally alien to them. But they should eventually pay Rs 10-15 every month per family. This is only one-tenth the depreciation and interest on the project, which thus involves a considerable subsidy. The Planning, Research and Action Division (PRAD) of the State of Uttar Pradesh, which is organising the project, has hired a manager for the plants and a trust of villagers has been formed to oversee it.

Meanwhile, the Department of Science and Technology is supporting an extensive R\&D programme to develop cheaper designs of bio-gas plants and identify new feedstocks which can replace or supplement cowdung. Two important designs have been developed: one by PRAD which is an improved version of a Chinese design supplied to Pakistan, and the other an indigenous design developed by the KVIC.

In the standard KVIC design, the fermentation pit (also called the digester) and the gas holder are two separate structures, the mild steel gas holder floating over the fermentation pit. This design is efficient, gas-tight and provides gas at a

\section{Sorry, for copyright reasons some images on this page may not be available online}

\section{A conventional KVIC bio-gas plant with a mild steel gas holder}

constant pressure, but the gas holder is susceptible to corrosion and cannot be made in the village.

In the Chinese design the fermentation pit and gas holder are combined into one brick structure, which makes it cheaper and easier to construct and maintain a biogas plant with a village's own resources. Although the initial versions suffered badly from gas leakages, PRAD workers now claim that their improved design is not only as efficient as the KVIC design but also half its cost. About 110 plants have been built in Uttar Pradesh and Rajasthan, and PRAD is organising training courses for constructing these plants, now called Janata (People's) Bio-gas Plants.

KVIC is meanwhile seriously evaluating its own new design in which both the digester and the gas holder are made of ferrocement. The digester is made up of a series of modular ferrocement rings which fit into each other, and the ferrocement gas holder slides into the digester. The farmer, has nothing to do but dig a suitable size pit. Some 100 such experimental plants have been set up and they are reported to be operating very satisfactorily. The ferrocement plants are about $20 \%$ cheaper than the conventional plants, but still slightly dearer than that of the Janata plants.

A hybrid design, incorporating a ferrocement gas holder with a conventional brick and mortar digester has been developed by the Structural Engineering Research Centre at Roorkee, and several voluntary groups are also working on new bio-gas plant designs. Mr J.C. Kapur of Kapur Solar Farms in New Delhi has developed a combined system of solar water heaters and bio-gas plants. The output of bio-gas plants falls drastically during the winter months, when minimum temperatures in northern India drop to near zero, and these are the months when more cooking energy is required. Solar heated water can keep the temperature in the digester at an optimum level and thus maintain the gas output. The bio-gas plant provides energy for cooking, to generate electricity for lighting, and also to take over from the solar plant for air conditioning when solar intensity is low. Kapur foresees a totally automatic interactive system.

\section{Searching for new feedstocks}

Simultaneously, several efforts are being made in various agricultural universities and research centres to find new feedstocks for bio-gas plants. The KVIC itself is experimenting with plants that use agricultural wastes (straw from wheat or rice, for example) with not more than 5\% dung. Another possibility is water hyacinth, a weed that grows prolifically in various parts of India. The PRAD workers have already found that a mixture of water hyacinth and dung in the ratio of $2: 3$, gives a gas output increased by $40-50 \%$ and also a slurry richer in nitrogen, phosphates and potash. The KVIC is also experimenting with bio-gas plants which use urine as a feedstock: in some states the villagers are beginning to show less aversion to using human wastes in bio-gas plants.

The KVIC proposes to set up five regional bio-gas experimental centres to try out various types of bio-gas plant with a range of feedstocks in different agroclimatic, socio-economic and resource conditions. This type of research should help to identify the best designs for different regions.

But despite this vast programme, bio-gas researchers continue to be treated as second-class citizens in energy research. Work at the Gobar Gas Research Station of PRAD in Ajitmal, for instance, is treated by research workers as an interim arrangement until they find a better job. Researchers still receive low salaries and suffer from job insecurity, conditions under which no Indian nuclear researcher, for instance, would ever work. Successive Prime Ministers have stated that bio-gas is a matter of national interest, and India still needs to implement fully this good intention. 